Pressure dependence of the super conducting transition temperat ure of the filled skut t er udi te YFe4P12

\begin{tabular}{|c|c|}
\hline 著者 & 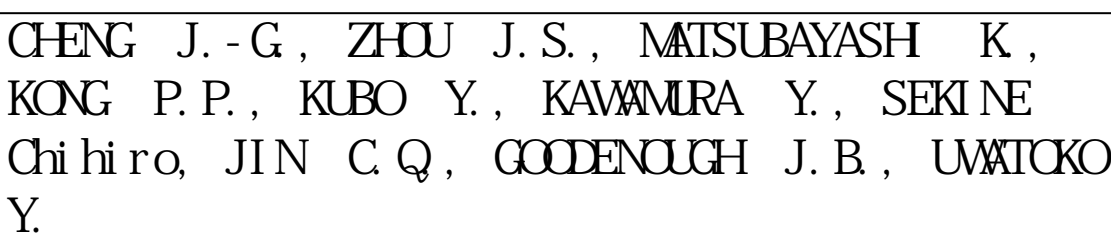 \\
\hline $\begin{array}{l}\text { j our nal or } \\
\text { publ i cat } \mathrm{i} \text { on } \mathrm{title}\end{array}$ & $\begin{array}{l}\text { Physi cal revi ew. Thi } r \text { d series. B, Condensed } \\
\text { matter and materi al s physi cs }\end{array}$ \\
\hline vol une & 88 \\
\hline nunber & 2 \\
\hline page $r$ ange & 2451424514 \\
\hline year & $2013-07-25$ \\
\hline URL & ht t p: //hdl . handl e. net /10258/2729 \\
\hline
\end{tabular}


Pressure dependence of the super conducting transition temperat ure of the filled skut t er udi te YFe4P12

\begin{tabular}{|c|c|}
\hline 著者 & 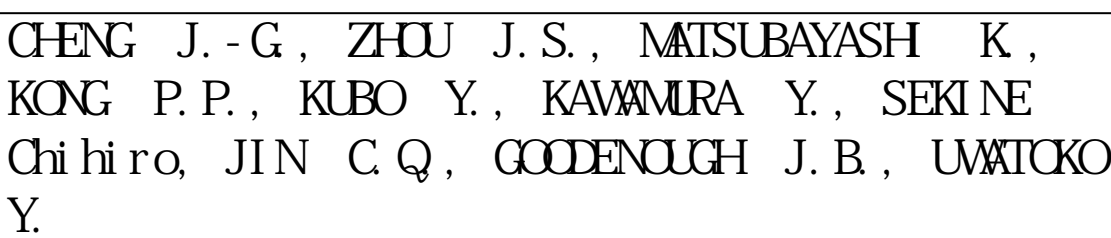 \\
\hline $\begin{array}{l}\text { j our nal or } \\
\text { publ i cat } \mathrm{i} \text { on } \mathrm{title}\end{array}$ & $\begin{array}{l}\text { Physi cal revi ew. Thi } r \text { d series. B, Condensed } \\
\text { matter and materi al s physi cs }\end{array}$ \\
\hline vol une & 88 \\
\hline nunber & 2 \\
\hline page $r$ ange & 2451424514 \\
\hline year & $2013-07-25$ \\
\hline URL & ht t p: //hdl . handl e. net /10258/2729 \\
\hline
\end{tabular}




\title{
Pressure dependence of the superconducting transition temperature of the filled skutterudite $\mathrm{YFe}_{4} \mathbf{P}_{12}$
}

\author{
J.-G. Cheng, ${ }^{1,2,3,{ }^{*}}$ J.-S. Zhou, ${ }^{2}$ K. Matsubayashi, ${ }^{1}$ P. P. Kong, ${ }^{3}$ Y. Kubo,${ }^{4}$ Y. Kawamura, ${ }^{5}$ C. Sekine, ${ }^{5}$ C. Q. Jin, ${ }^{3}$ \\ J. B. Goodenough, ${ }^{2}$ and Y. Uwatoko ${ }^{1}$ \\ ${ }^{1}$ Institute for Solid State Physics, University of Tokyo, Kashiwa 277-8581, Japan \\ ${ }^{2}$ Materials Science and Engineering Program/Mechanical Engineering, University of Texas at Austin, Austin, Texas 78712, USA \\ ${ }^{3}$ Beijing National Laboratory for Condensed Matter Physics and Institute of Physics, Chinese Academy of Sciences, Beijing 100190, China \\ ${ }^{4}$ Department of Physics, College of Humanities and Science, Nihon University, Tokyo 156-8550, Japan \\ ${ }^{5}$ Muroran Institute of Technology, 27-1 Mizumoto, Muroran-shi 050-8585, Japan
}

(Received 15 June 2013; published 25 July 2013)

\begin{abstract}
We have studied the pressure dependence of the superconducting transition temperature $T_{c}$ of the filled skutterudite $\mathrm{YFe}_{4} \mathrm{P}_{12}$ under various quasihydrostatic pressures up to $8 \mathrm{GPa}$. DC magnetization measurements up to $1.2 \mathrm{GPa}$ in a piston-cylinder cell yields a linear increase of $T_{c}$ with a positive coefficient $d T_{c} / d P=1$ $\mathrm{K} / \mathrm{GPa}$. Resistivity measurements up to $8 \mathrm{GPa}$ in a cubic anvil apparatus show that $T_{c}$ increases to $9.3 \mathrm{~K}$ at $8 \mathrm{GPa}$, but the slope decreases gradually with increasing pressure. Besides the previously reported $\mathrm{LaFe}_{4} \mathrm{P}_{12}, \mathrm{YFe}_{4} \mathrm{P}_{12}$ becomes the second filled skutterudite superconductor that exhibits a positive pressure coefficient $d T_{c} / d P$ in a broad pressure range. The observed large $d T_{c} / d P>0$ of $\mathrm{YFe}_{4} \mathrm{P}_{12}$ can be rationalized by our band-structure calculations that show an enhancement of density of states at Fermi energy and the Hopfield parameter under pressure at least up to $8 \mathrm{GPa}$. On the other hand, similar calculations predict a $d T_{c} / d P<0$ for $\mathrm{YRu}_{4} \mathrm{P}_{12}$.
\end{abstract}

DOI: 10.1103/PhysRevB.88.024514

PACS number(s): 74.62.Fj, 74.70.Xa, 74.20.Pq

Filled skutterudites with a general chemical formula $R M_{4} X_{12}$ (usually $R=$ rare earth or alkaline earth: $M=$ $\mathrm{Fe}, \mathrm{Ru}, \mathrm{Os}, \mathrm{Co}, \mathrm{Rh}$, Ir; $X=\mathrm{P}$, As, or $\mathrm{Sb}$ ) consist of an important material family exhibiting a broad range of intriguing physical phenomena, such as superconductivity, ${ }^{1,2}$ heavy fermion behavior, ${ }^{2}$ Kondo insulating behavior, ${ }^{3}$ metalinsulator transition, ${ }^{4,5}$ and various magnetic ordering, ${ }^{6}$ as well as excellent thermoelectric performances. ${ }^{7}$ As summarized in Table I, at least 19 filled skutterudites have been reported to be superconducting materials with $T_{c}$ up to $17 \mathrm{~K}$. Most of these superconductors have been classified as BardeenCooper-Schrieffer (BCS) superconductors, which usually exhibit a negative pressure coefficient of the superconducting transition temperature $T_{c}$ owing to lattice stiffening under pressure. ${ }^{8}$ Based on the available high-pressure studies in the literature, this general rule is followed for most skutterudite superconductors except for $\mathrm{LaFe}_{4} \mathrm{P}_{12}$ (see Ref. 9), which shows a relatively large positive $d T_{c} / d P=+0.72 \mathrm{~K} / \mathrm{GPa}$ up to $1.8 \mathrm{GPa}$, as shown in Table I. In view of the negative $d T_{c} / d P$ for $M=\mathrm{Ru}$ and Os but positive for $M=\mathrm{Fe}$ in the series of $\mathrm{LaM}_{4} \mathrm{P}_{12}$, DeLong and Meisner ${ }^{9}$ have interpreted the pressure effect on $T_{c}$ for these filled skutterudite superconductors in terms of two competing contributions: (1) a universal decrease of $T_{c}$ under pressure due to the compression of the skutterudite lattice, and (2) an enhancement of $T_{c}$ due to a compression of $\mathrm{La}$ and its local environment. The latter argument is based on the observations that pure La metal ${ }^{10}$ and many La-containing intermetallic superconductors ${ }^{11}$ exhibit a positive $d T_{c} / d P$ due to an increase of the density of states (DOS) of $4 f$ bands near the Fermi level under pressure. Taking into account the unique structural characteristic of these filled skutterudites $\mathrm{La}_{4} \mathrm{P}_{12}$ ( $M=\mathrm{Fe}, \mathrm{Ru}$, and Os; see inset of Fig. 1), they argued that the latter positive pressure effect becomes effective only where the $\mathrm{La}$ atoms inside the $\left(\mathrm{MP}_{6}\right)_{4}$ cages are under compression as in $\mathrm{LaFe}_{4} \mathrm{P}_{12}$ (see Ref. 9).
Although the above model provided a simple explanation for the unique positive $d T_{c} / d P$ of $\mathrm{LaFe}_{4} \mathrm{P}_{12}$, the structural features of the $\mathrm{La}$ atoms in the filled skutterudite structure are inside $\left(\mathrm{FeP}_{6}\right)_{4}$ cages and are well separated (e.g., La-La distance $\sim 6.78 \AA),{ }^{12}$ which makes the model less convincing. In contrast with the La-containing intermetallic compounds in which the superconductivity is determined mainly by lanthanum (La-La separation $~ 3.4-3.8 \AA$ ), ${ }^{11}$ electronic structure calculations ${ }^{13}$ on $\mathrm{LaFe}_{4} \mathrm{P}_{12}$ have suggested that its superconductivity at ambient pressure should be associated largely with the phosphorous sublattice, which forms a strong covalent-bonded $\mathrm{P}_{4}$ ring and dominates the DOS at the Fermi level $N\left(E_{f}\right)$. In the series of $R \mathrm{Fe}_{4} \mathrm{P}_{12}$, $\mathrm{YFe}_{4} \mathrm{P}_{12}$ obtained under high pressure and high temperature (HPHT) conditions has been reported to be superconductive with $T_{\mathrm{c}}{ }^{\text {onset }} \approx 7 \mathrm{~K}^{14}$ It is well known that $\mathrm{Y}$ metal is not superconducting above $6 \mathrm{mK}$ at ambient pressure and becomes superconducting only under pressure $P>11 \mathrm{GPa} .{ }^{15}$ Thus, the superconductivity of $\mathrm{YFe}_{4} \mathrm{P}_{12}$ and its variation of $T_{c}$ with pressure are unlikely determined by direct $\mathrm{Y}-\mathrm{Y}$ bonding. To shed more light on the unusual positive $d T_{c} / d P$ of $\mathrm{LaFe}_{4} \mathrm{P}_{12}$ and the mechanism for the superconductivity of $R \mathrm{Fe}_{4} \mathrm{P}_{12}$ ( $R=\mathrm{La}, \mathrm{Y}$ ), we have investigated the dependence of $T_{c}$ for $\mathrm{YFe}_{4} \mathrm{P}_{12}$ under quasihydrostatic pressures up to $8 \mathrm{GPa}$ with different high-pressure techniques. DC magnetization measurements up to $1.2 \mathrm{GPa}$ in a piston-cylinder cell show a linear increase of $T_{c}$ with a large positive coefficient $d T_{c} / d P=$ $1 \mathrm{~K} / \mathrm{GPa}$. Resistivity measurements up to $8 \mathrm{GPa}$ in a cubic multianvil apparatus show that $T_{c}$ keeps climbing to $9.3 \mathrm{~K}$ at $8 \mathrm{GPa}$, but the slope decreases gradually with increasing pressure. Resistance measurements in a diamond anvil cell (DAC) indicated that $T_{c}$ is suppressed at higher pressures. Taking into account the structure characteristics revealed by our structural refinement of $\mathrm{YFe}_{4} \mathrm{P}_{12}$, the direct $\mathrm{Y}-\mathrm{Y}$ bonding is unlikely to contribute the positive pressure effect on $T_{c}$. 
TABLE I. Summary of the superconducting transition temperature $T_{c}$ and its pressure coefficients $d T_{c} / d P$ and $d \ln T_{c} / d P$ for all known filled skutterudite superconductors.

\begin{tabular}{|c|c|c|c|c|c|c|}
\hline \multicolumn{3}{|c|}{$R M_{4} X_{12}$} & \multirow{2}{*}{$\frac{T_{c}(\mathrm{~K})}{4.1}$} & \multirow{2}{*}{$\frac{d T_{c} / d P(\mathrm{~K} / \mathrm{GPa})}{+0.72}$} & \multirow{2}{*}{$\frac{d \ln T_{c} / d P\left(10^{-2} \mathrm{GPa}^{-1}\right)}{+17.56}$} & \multirow{2}{*}{$\begin{array}{c}\text { Refs. } \\
9\end{array}$} \\
\hline $\mathrm{La}$ & $\mathrm{Fe}$ & $\mathrm{P}$ & & & & \\
\hline & $\mathrm{Ru}$ & $\mathrm{P}$ & 7.2 & -0.16 & -2.22 & 9 \\
\hline & & As & 10.3 & -0.40 & -3.88 & 45 \\
\hline & & $\mathrm{Sb}$ & 3.58 & I & l & 46 \\
\hline & Os & $\mathrm{P}$ & 1.8 & -0.095 & 5.28 & 9 \\
\hline & & As & 3.2 & I & I & 45 \\
\hline & & $\mathrm{Sb}$ & 0.74 & l & l & 47 \\
\hline & $\mathrm{Rh}$ & $\mathrm{P}$ & $13.6 \sim 17$ & $-(0.3 \sim 0.5)$ & $-(2.2 \sim 3.7)$ & 48 \\
\hline \multirow[t]{3}{*}{$\mathrm{Y}$} & $\mathrm{Fe}$ & $\mathrm{P}$ & 5.6 & +1 & +17.8 & This work \\
\hline & $\mathrm{Ru}$ & $\mathrm{P}$ & 8.5 & l & / & 49 \\
\hline & Os & $\mathrm{P}$ & 3 & I & l & 50 \\
\hline \multirow[t]{4}{*}{$\operatorname{Pr}$} & $\mathrm{Ru}$ & $\mathrm{P}$ & $2 @ 14.7 \mathrm{GPa}$ & l & l & 51 \\
\hline & & As & 2.4 & l & l & 52 \\
\hline & & $\mathrm{Sb}$ & 1.1 & -0.21 & -19.1 & 48 \\
\hline & Os & $\mathrm{Sb}$ & 1.85 & I & l & 2 \\
\hline $\mathrm{La}$ & & & 8.3 & l & l & 31 \\
\hline $\operatorname{Pr}$ & Pt & Ge & 7.9 & I & I & \\
\hline $\mathrm{Sr}$ & $\mathrm{Pt}$ & Ge & 5.4 & I & I & \\
\hline $\mathrm{Ba}$ & & & 5.0 & l & l & \\
\hline
\end{tabular}

Instead, the large positive $d T_{c} / d P$ can be explained by our band-structure calculations that show a dramatic enhancement of $N\left(E_{f}\right)$ and the Hopfield parameter $(H-p)$. Our similar calculations predict a negative $d T_{c} / d P$ for $\mathrm{YRu}_{4} \mathrm{P}_{12}$, which should be applicable to the $\mathrm{LaM}_{4} \mathrm{P}_{12}(\mathrm{~T}=\mathrm{Ru}, \mathrm{Os}){ }^{9}$

Similar to the previous report by Shirotani et al., ${ }^{14}$ polycrystalline $\mathrm{YFe}_{4} \mathrm{P}_{12}$ samples used in the present study were obtained by sintering a stoichiometric mixture of $\mathrm{Y}, \mathrm{Fe}$, and red phosphorous powders at $5 \mathrm{GPa}$ and $1100{ }^{\circ} \mathrm{C}$ for $1 \mathrm{~h}$ with a Walker-type multianvil module (Rockland Research Co.). All sample preparations were performed in an Ar-filled glove box.

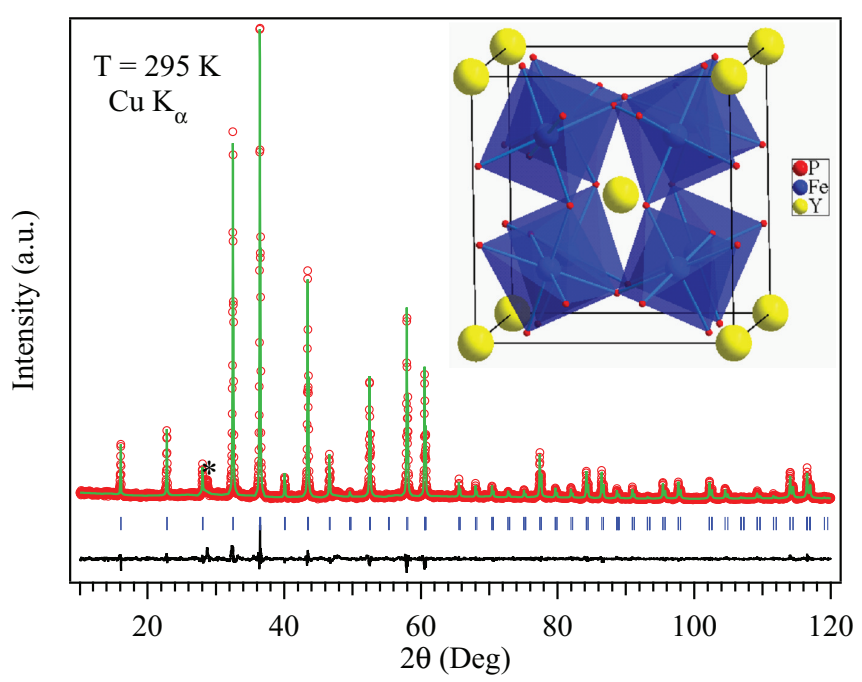

FIG. 1. (Color online) Observed (open circle), calculated (solid line), and difference (bottom) XRD profiles of $\mathrm{YFe}_{4} \mathrm{P}_{12}$ obtained under HPHT conditions. The vertical marks are allowed Bragg positions. A trace amount of unknown impurity is indicated by an asterisk $\left(^{*}\right)$. Inset displays the unit-cell crystal structure of $\mathrm{YFe}_{4} \mathrm{P}_{12}$.
A hexagonal boron nitride (h-BN) capsule was used directly as the sample container. Details about the sample assembly and procedures for HPHT synthesis can be found elsewhere. ${ }^{16}$ The surface of the as-obtained HP product was polished before measurements of structural and physical properties.

Phase purity of the obtained $\mathrm{YFe}_{4} \mathrm{P}_{12}$ samples was examined by powder $\mathrm{X}$-ray diffraction (XRD) at room temperature with a Philips $\mathrm{X}$ 'pert diffractometer $\left(\mathrm{Cu} \mathrm{K}_{\alpha}\right.$ radiation). The XRD pattern recorded in the $2 \theta$ range from 15 to $120^{\circ}$ with a step size $0.02^{\circ}$ and a dwell time $10 \mathrm{~s}$ was analyzed with the Rietveld method by using the FULLPROF program. ${ }^{17}$ Magnetic properties were measured with a commercial superconducting quantum interference device (SQUID) magnetometer (Quantum Design). Electrical resistivity and thermal conductivity were measured with a standard four-probe method and a steady-state method, respectively. A homemade setup was used to measure the thermoelectric power. The magnetization measurements under pressure were performed with a pistoncylinder device fit into the SQUID magnetometer. The sample, together with a piece of Sn as the pressure manometer, was sealed in a Teflon cell filled with a mixture of glycerin and water as the pressure-transmitting medium (PTM). The temperature dependence of resistivity under quasihydrostatic pressures up to $8 \mathrm{GPa}$ was performed in a cubic multianvil apparatus. ${ }^{18}$ The preheated pyrophyllite cube was used as gasket and a mixture of glycerin and water as the PTM. Measurements of resistance up to $16 \mathrm{GPa}$ were performed in a DAC. $\mathrm{MgO}$ fine powder was used as the insulating layer on a stainless steel (T301) gasket, and h-BN was used as the solid PTM. The pressure applied at room temperature was monitored by the ruby-fluorescence method.

The powder XRD pattern shown in Fig. 1 confirms that the $\mathrm{YFe}_{4} \mathrm{P}_{12}$ sample is nearly single phase with a trace amount of unknown impurity, as indicated by an asterisk $\left(^{*}\right)$. To obtain detailed structural information, we have refined the XRD 
TABLE II. Atomic coordinates and isotropic thermal factors $B_{\text {iso }}$ for $\mathrm{YFe}_{4} \mathrm{P}_{12}$ from powder $\mathrm{XRD}^{\mathrm{a}}$ at $295 \mathrm{~K}$; space group: cubic $I m-3$ (No. 204), $a=7.7913(1) \AA, V=472.97(1) \AA^{3}, Z=2$.

\begin{tabular}{lccccc}
\hline \hline Atom & Site & $x$ & $y$ & $z$ & $B_{\text {iso }}\left(\AA^{2}\right)$ \\
\hline $\mathrm{Y}$ & $2 a$ & 0 & 0 & 0 & $1.72(9)$ \\
$\mathrm{Fe}$ & $8 c$ & 0.25 & 0.25 & 0.25 & $1.63(7)$ \\
$\mathrm{P}$ & $24 g$ & 0 & $0.1472(4)$ & $0.3519(3)$ & $1.51(7)$ \\
\hline \hline
\end{tabular}

a Discrepancy factors: $R_{\mathrm{p}}=8.66 \%, R_{\mathrm{wp}}=11.8 \%, R_{\exp }=9.60 \%$, $\chi^{2}=1.51, R_{\text {Bragg }}=4.41 \%$.

pattern by taking the structure of $\mathrm{LaFe}_{4} \mathrm{P}_{12}$ as the starting model, ${ }^{12}$ which is defined in the cubic $I m-3$ (No. 204) space group with $\mathrm{Y}$ at $2 a(0,0,0), \mathrm{Fe}$ at $8 c(1 / 4,1 / 4,1 / 4)$, and $\mathrm{P}$ at $24 g(0, y, z)$ positions, respectively. The goodness of refinement is illustrated in Fig. 1, and a schematic view of the unit-cell crystal structure is displayed in the inset of Fig. 1. The final atomic positions after the Rietveld refinement are listed in Table II. Selected bond lengths and angles of $\mathrm{YFe}_{4} \mathrm{P}_{12}$ are compared with those of $\mathrm{LaFe}_{4} \mathrm{P}_{12}$ in Table III. The obtained cubic lattice constant $a=7.7913(1) \AA$ is in excellent agreement with that reported by Shirotani et al. ${ }^{14}$ of $a=7.7896(1) \AA$ for $\mathrm{YFe}_{4} \mathrm{P}_{12}$.

It should be noted that no structural refinement has been performed for the lanthanide $R \mathrm{Fe}_{4} \mathrm{P}_{12}(R=\mathrm{Dy}, \ldots, \mathrm{Lu}$, and Y) except for $R=\mathrm{Yb}^{19}$ as far as we know. The structural refinement may provide an important clue to understand the essential role of high-pressure synthesis in stabilizing the filled skutterudite structure for the smaller lanthanides. As a general observation, under ambient pressure the pnictogen's coordination $(y, z)$ in most unfilled binary skutterudites is located below the Oftedal line, $y+z=1 / 2$ in the $y$ versus $z$ plot, whereas that of filled skutterudites is located above the Oftedal line. ${ }^{20}$ High-pressure synthesis has been shown to be an effective approach in order to fill the binary skutterudites below the Oftedal line. ${ }^{21,22}$ The obtained Phosphorus coordination $(0.1472,0.3519)$ in Table II is located slightly below the Oftedal line, which can thus explain why a moderate pressure is required in order to stabilize the filled skutterudite structure for $\mathrm{YFe}_{4} \mathrm{P}_{12}$. To further verify this argument, systematic structural refinements on other heavy lanthanides $R \mathrm{Fe}_{4} \mathrm{P}_{12}$ are highly desirable.

As shown in Table III, replacement of smaller $\mathrm{Y}$ for $\mathrm{La}$ results in negligible modifications for the $\left(\mathrm{FeP}_{3}\right)_{4}$ framework in terms of the P-Fe-P and Fe-P-Fe bond angles as well as the Fe-P bond length. The reductions of $R-\mathrm{P}$ and $R-\mathrm{Fe}$ interatomic distances, i.e., $0.04 \AA$ and $0.017 \AA$, respectively,

TABLE III. Comparison of the bond lengths $(\AA)$ and angles $\left(^{\circ}\right)$ between $\mathrm{YFe}_{4} \mathrm{P}_{12}$ and $\mathrm{LaFe}_{4} \mathrm{P}_{12}$.

\begin{tabular}{lccc}
\hline \hline & $\mathrm{YFe}_{4} \mathrm{P}_{12}$ & \multicolumn{2}{c}{$\mathrm{LaFe}_{4} \mathrm{P}_{12}\left(\mathrm{Ref}^{2} 12\right)$} \\
\hline $\mathrm{Y}-\mathrm{P}$ & $2.972(2)(\times 12)$ & $\mathrm{La}-\mathrm{P}$ & $3.012(\times 12)$ \\
$\mathrm{Y}-\mathrm{Fe}$ & $3.374(2)(\times 8)$ & $\mathrm{La}-\mathrm{Fe}$ & $3.391(\times 8)$ \\
$\mathrm{Fe}-\mathrm{P}$ & $2.251(2)(\times 6)$ & $\mathrm{Fe}-\mathrm{P}$ & $2.259(\times 6)$ \\
$\mathrm{P}-\mathrm{Fe}-\mathrm{P}$ & $97.1(1)$ & $\mathrm{P}-\mathrm{Fe}-\mathrm{P}$ & 97.9 \\
$\mathrm{P}-\mathrm{Fe}-\mathrm{P}$ & $82.9(1)$ & $\mathrm{P}-\mathrm{Fe}-\mathrm{P}$ & 82.1 \\
$\mathrm{Fe}-\mathrm{P}-\mathrm{Fe}$ & $119.86(5)$ & $\mathrm{Fe}-\mathrm{P}-\mathrm{Fe}$ & 120.1 \\
\hline \hline
\end{tabular}

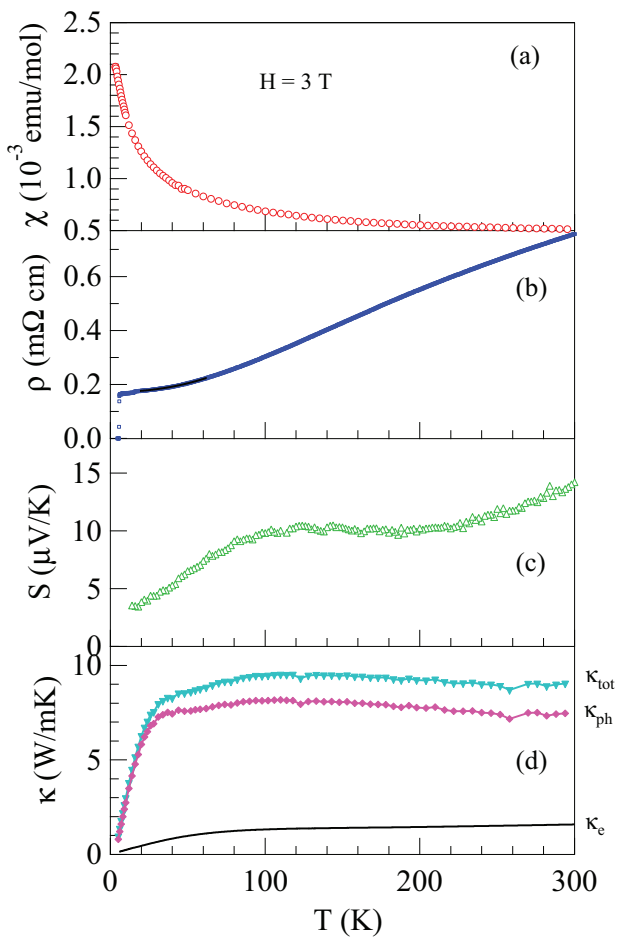

FIG. 2. (Color online) Temperature dependence of the (a) magnetic susceptibility $\chi(T)$ measured under $H=3 \mathrm{~T}$ after ZFC, (b) resistivity $\rho(T)$, (c) thermopower $S(T)$, and (d) thermal conductivity $\kappa(T)$ in a wide temperature range $(2-300 \mathrm{~K})$.

from $\mathrm{LaFe}_{4} \mathrm{P}_{12}$ to $\mathrm{YFe}_{4} \mathrm{P}_{12}$, are much smaller relative to the ionic-radius change between $\mathrm{La}^{3+}$ and $\mathrm{Y}^{3+}$, i.e., $0.141 \AA$ in a hard-sphere model. In addition, the observed Y-P distance of 2.972(2) $\AA$ in $\mathrm{YFe}_{4} \mathrm{P}_{12}$ is longer than that of $2.8266 \AA$ in $\mathrm{YP}^{23}$ and of $2.945 \AA$ in $\mathrm{YP}_{5}$ (see Ref. 24). These observations thus indicated that the $\mathrm{Y}$ ions in $\mathrm{YFe}_{4} \mathrm{P}_{12}$ are loosely bonded to the $\left(\mathrm{FeP}_{3}\right)_{4}$ cages in comparison with $\mathrm{La}$ in $\mathrm{LaFe}_{4} \mathrm{P}_{12}$. In other words, $\mathrm{YFe}_{4} \mathrm{P}_{12}$ could be more compressible than $\mathrm{LaFe}_{4} \mathrm{P}_{12}$.

Before we move on to the pressure effect on the superconductivity of $\mathrm{YFe}_{4} \mathrm{P}_{12}$, we first describe the physical properties of its normal state. Figure 2 shows the temperature dependences of (a) magnetic susceptibility $\chi(T)$, (b) electrical resistivity $\rho(T)$, (c) thermoelectric power $S(T)$, and (d) thermal conductivity $\kappa(T)$ in the temperature range 2-300 K. The $\chi(T)$ curve recorded under an external magnetic field $H=3 \mathrm{~T}$ after zero-field cooling (ZFC) exhibits a paramagnetic behavior with a weak temperature dependence, indicating the absence of a localized magnetic moment on iron, which is in agreement with the Mössbauer results for $\mathrm{LaFe}_{4} \mathrm{P}_{12}$ (see Ref. 25). Such a nonmagnetic character of iron has been ascribed to the strong covalent bonding with the octahedrally coordinated phosphorous atoms. ${ }^{13}$ Electronic structure calculations ${ }^{13}$ of $\mathrm{LaFe}_{4} \mathrm{P}_{12}$ have shown that the highest occupied band consists mainly of the $\mathrm{Fe} 3 d$ and phosphorous $3 s / 3 p$ orbitals, which are responsible for the metallic conductivity shown in Fig. 2(b). $\rho(T)$ of our $\mathrm{YFe}_{4} \mathrm{P}_{12}$ sample is almost identical to that reported by Shirontani et al. ${ }^{14}$ It is interesting to note that $\rho(T)$ in the normal state follows the Fermi-liquid behavior, viz. $\rho=\rho_{0}+\mathrm{AT}^{2}$, at low temperatures. However, the behavior of $\rho(T)$ at higher 


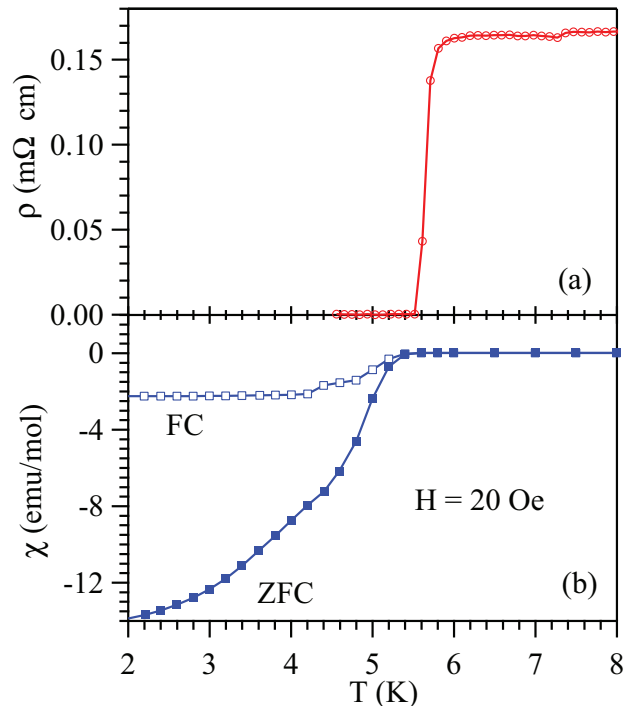

FIG. 3. (Color online) Temperature dependence of (a) resistivity $\rho(T)$ and (b) magnetic susceptibility $\chi(T)$ measured under $H=20$ Oe after ZFC and FC below $8 \mathrm{~K}$ for $\mathrm{YFe}_{4} \mathrm{P}_{12}$. The zero resistivity and diamagnetic signal are observed below $5.5 \mathrm{~K}$.

temperatures resembles the feature of resistivity saturation found in $\mathrm{Nb}_{3} \mathrm{Sb}^{26}$ We have calculated the Kadowaki-Woods ratio $\mathrm{A} / \gamma^{2}$ on the basis of the power-law fitting to $\rho(T)$ and the $\gamma$ from the specific-heat measurement; ${ }^{14} \mathrm{~A} / \gamma^{2}=$ $7.5 \times 10^{-6} \mu \Omega \cdot \mathrm{cm} \cdot \mathrm{mol}^{2} \cdot \mathrm{K}^{2} /(\mathrm{mJ})^{2}$ is close to the universal value of $10^{-5} \mu \Omega \cdot \mathrm{cm} \cdot \mathrm{mol}^{2} \cdot \mathrm{K}^{2} /(\mathrm{mJ})^{2}$ for most heavy Fermion compounds. ${ }^{27}$ Instead of the Mott diffusive formula $S(T) \propto$ $T$ for metals, $S(T)$ in Fig. 2(c) displays clear slope changes with decreasing temperature. These observations indicate that the electronic structure near the Fermi level exhibits a subtle evolution as a function of temperature. Although the structural analysis indicated a relatively weak bonding of $\mathrm{Y}$ to the $\left(\mathrm{FeP}_{3}\right)_{4}$ cage, the relatively high thermal conductivity in Fig. 2(d) rules out the possibility of a rattling motion found in some skutterudites. After subtracting the electronic contribution $\kappa_{e}=\mathrm{LT} / \rho$ according to the Widemann-Franz law, where $\mathrm{L}=2.44 \times 10^{-8} \mathrm{~W} \cdot \Omega \cdot \mathrm{K}^{-2}$, it is clear that the lattice part dominates the heat transfer with a room-temperature value of $\sim 8 \mathrm{~W} \cdot \mathrm{m}^{-1} \cdot \mathrm{K}^{-1}$.

Now we turn to the superconductivity of $\mathrm{YFe}_{4} \mathrm{P}_{12}$ and the pressure effect on $T_{c}$. The ambient-pressure $\rho(T)$ data in Fig. 3(a) shows that the $\mathrm{YFe}_{4} \mathrm{P}_{12}$ sample reaches zero resistivity below $5.5 \mathrm{~K}$, where the Meissner signal in $\chi(T)$ appears [see Fig. 3(b)]. We first monitored the pressure dependence of the superconducting transition temperature $T_{c}$ of $\mathrm{YFe}_{4} \mathrm{P}_{12}$ by measuring its dc magnetization $M(T)$ under various quasihydrostatic pressures up to $1.22 \mathrm{GPa}$ with a miniature $\mathrm{BeCu}$ piston-cylinder cell fit into a SQUID magnetometer. The high-pressure $M(T)$ data are shown in the main panel of Fig. 4. As can be seen, with increasing pressure $T_{c}$ of $\mathrm{YFe}_{4} \mathrm{P}_{12}$ increases while $T_{c}$ of $\mathrm{Sn}$ as a pressure manometer decreases accordingly. We defined $T_{c}$ as the crossing point of two extrapolated straight lines on the $M(T)$ curve above and below $T_{c}$. As shown in the inset of Fig. 4, $T_{c}$ of $\mathrm{YFe}_{4} \mathrm{P}_{12}$ increases linearly with a coefficient $d T_{c} / d P=+1.0 \mathrm{~K} / \mathrm{GPa}$, which is larger than that of $+0.72 \mathrm{~K} / \mathrm{GPa}$ for $\mathrm{LaFe}_{4} \mathrm{P}_{12}$ (see Ref. 9). $\mathrm{YFe}_{4} \mathrm{P}_{12}$

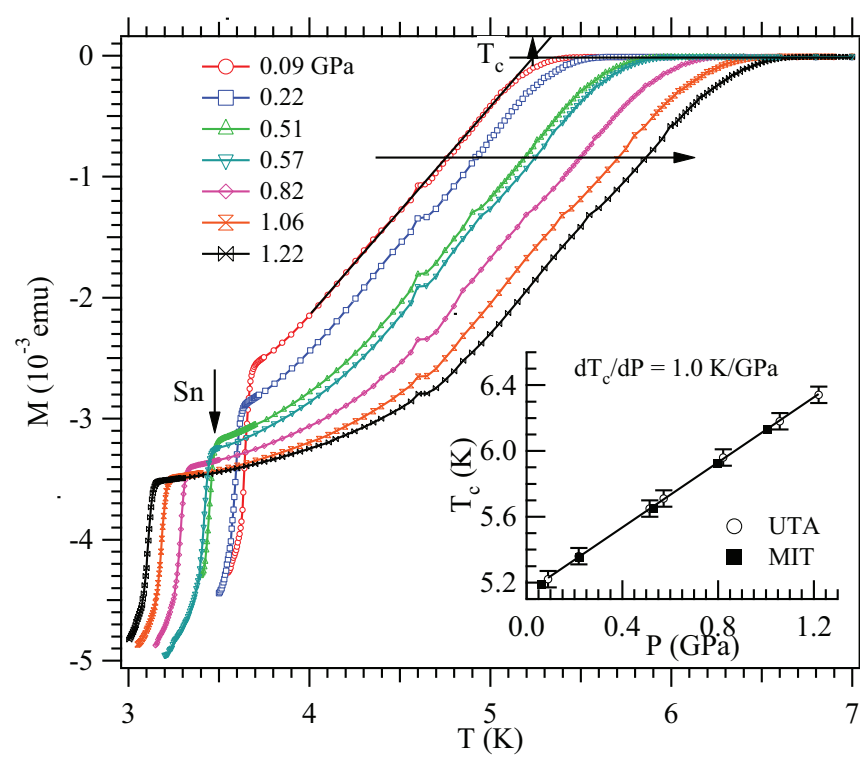

FIG. 4. (Color online) Temperature dependence of magnetization $M(T)$ of $\mathrm{YFe}_{4} \mathrm{P}_{12}$ and $\mathrm{Sn}$ used as pressure manometer under various quasihydrostatic pressures up to $1.22 \mathrm{GPa}$ measured with a pistoncylinder device inside the SQUID magnetometer. Inset shows the pressure dependence of $T_{c}$.

thus becomes the second filled skutterudite superconductor exhibiting a positive pressure coefficient $d T_{c} / d P$, as shown in Table I. In order to clarify whether the pressure dependence of $T_{c}$ is sample dependent, we have measured the $M(T)$ under pressure on samples from different institutes, the University of Texas at Austin (UTA) and the Muroran Institute of Technology (MIT). As shown in the inset of Fig. 4, the two samples have a nearly identical $T_{c}$ and its pressure coefficient.

Such a large pressure coefficient of $T_{c}$ motivated us to check how $T_{c}$ changes in an extended pressure range. For this purpose, we measured the resistivity $\rho(T)$ of a $\mathrm{YFe}_{4} \mathrm{P}_{12}$ sample prepared at UTA from 4.2 to $300 \mathrm{~K}$ under various quasihydrostatic pressures up to $8 \mathrm{GPa}$ with a cubic anvil apparatus. The $\rho(T)$ data are plotted in the main panel of Fig. 5. We defined $T_{c}=\left(T_{c}^{\text {onset }}+T_{c}^{\text {zero }}\right) / 2$ as the middle point between the onset temperature of superconductivity, $T_{c}^{\text {onset }}$, and the zero-resistivity temperature, $T_{c}^{\text {zero }}$, while the error bar of $T_{c}$ represents the transition width $\Delta T_{c}=\left(T_{c}^{\text {onset }}-T_{c}^{\text {zero }}\right) / 2$. The pressure dependence of $T_{c}$ is shown in the inset of Fig. 5. It should be emphasized that the superconductivity transition remains sharp up to $8 \mathrm{GPa}$ (see the inset of Fig. 5), which indicates a good hydrostatic pressure condition during the measurement. With increasing pressure, $T_{c}$ increases almost linearly from $5.6 \mathrm{~K}$ at ambient pressure to $8.3 \mathrm{~K}$ at $5 \mathrm{GPa}$ with a positive slope $d T_{c} / d P=+0.53(2) \mathrm{K} / \mathrm{GPa}$, and then $T_{c}$ starts to deviate from the line and reaches $9.3 \mathrm{~K}$ at $8 \mathrm{GPa}$. It looks as though the $T_{c}$ of $\mathrm{YFe}_{4} \mathrm{P}_{12}$ will saturate at higher pressures.

In order to check if $T_{c}$ will indeed follow a dome-shape $T_{c}(P)$ curve as found in cuprates, ${ }^{8}$ we have performed the measurement of resistance $R(T)$ of $\mathrm{YFe}_{4} \mathrm{P}_{12}$ with a DAC. Although no zero resistance can be observed in this case due to the nonhydrostatic pressure conditions by using a solid PTM, $R(T)$ exhibits a clear drop at the superconducting transition, as 


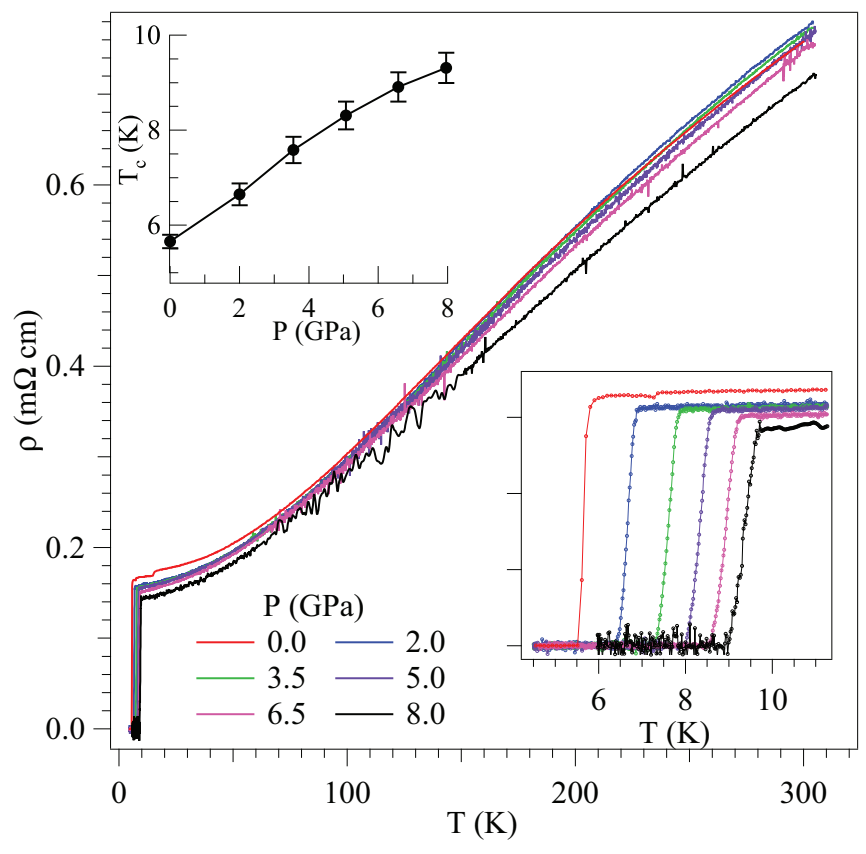

FIG. 5. (Color online) Temperature dependence of resistivity $\rho(T)$ of $\mathrm{YFe}_{4} \mathrm{P}_{12}$ under various quasihydrostatic pressures up to $8 \mathrm{GPa}$ measured with a cubic anvil apparatus. Insets show the pressure dependence of $T_{c}$ and a zoom-in plot of $\rho(T)$ near $T_{c}$.

shown in Fig. 6. $T_{c}$ of $\mathrm{YFe}_{4} \mathrm{P}_{12}$ first increases with increasing pressure, which is consistent with the above results; then, $T_{c}$ decreases gradually with further increasing pressure. It should be noted that the pressures inside the DAC were measured at room temperature, which may be different from the actual pressure at $T<10 \mathrm{~K}$. This factor makes the quantitative comparison of the pressure effect on $T_{c}$ in Figs. 5 and 6 impossible, but the results in Fig. 6 indeed tell us that the $T_{c}$ of $\mathrm{YFe}_{4} \mathrm{P}_{12}$ undergoes a maximum for $P>8 \mathrm{GPa}$. Therefore, our present high-pressure studies on $\mathrm{YFe}_{4} \mathrm{P}_{12}$ show that its superconducting transition temperature $T_{c}$ is first enhanced

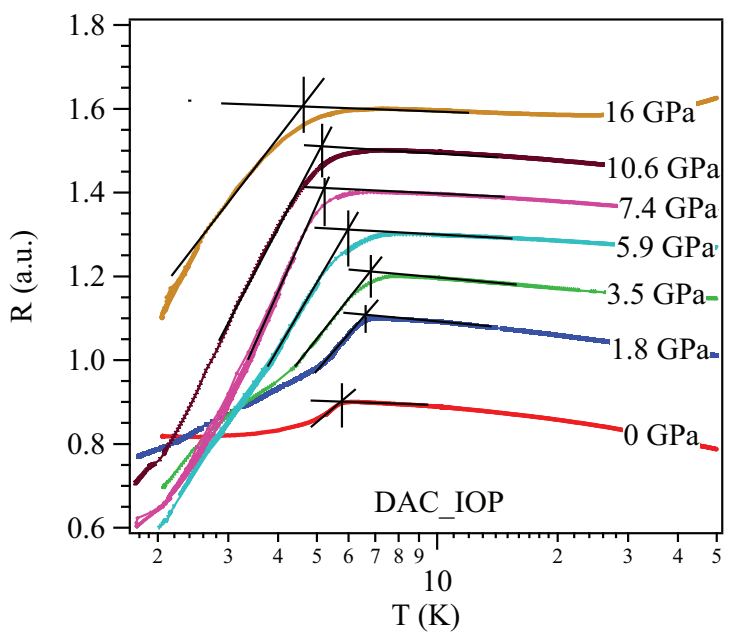

FIG. 6. (Color online) Temperature dependence of resistance $R(T)$ of $\mathrm{YFe}_{4} \mathrm{P}_{12}$ up to $16 \mathrm{GPa}$ measured with a diamond anvil cell. The pressures were measured at room temperature and are expected to be different from the actual value at low temperatures $T<10 \mathrm{~K}$. with the application of external pressure at least up to $8 \mathrm{GPa}$, above which $T_{c}$ is suppressed by pressure, as observed in other filled skutterudite superconductors shown in Table I. A similar trend of $T_{c}$ versus pressure has also been observed in the $\mathrm{LaFe}_{4} \mathrm{P}_{12}$ (see Ref. 28). We now discuss the possible origin for the positive pressure effect on $T_{c}$ of $R \mathrm{Fe}_{4} \mathrm{P}_{12}(R=\mathrm{La}, \mathrm{Y})$ in a broad pressure range.

In the model by DeLong and Meisner, ${ }^{9}$ a positive $d T_{c} / d P$ in $\mathrm{LaFe}_{4} \mathrm{P}_{12}$ has been related to a $d T_{c} / d P>0$ in the La metal. Since a $d T_{c} / d P>0$ has been observed in the $\mathrm{Y}$ metal, ${ }^{15}$ our observation on $\mathrm{YFe}_{4} \mathrm{P}_{12}$ seems to be in line with their argument. A closer inspection of the characteristics of crystal and electronic structures of $R \mathrm{Fe}_{4} \mathrm{P}_{12}$, however, raises questions about whether the argument is applicable to $\mathrm{YFe}_{4} \mathrm{P}_{12}$. (1) $\mathrm{Y}$ metal is not a superconductor at ambient pressure, and its $T_{c}$ remains below $4 \mathrm{~K}$ for $\mathrm{P}=30 \mathrm{GPa}^{15}$ (2) The structural refinements revealed no compression on the filling $\mathrm{Y}$ atoms within the $\left(\mathrm{FeP}_{3}\right)_{4}$ cages. (3) The pressure coefficient of $\mathrm{YFe}_{4} \mathrm{P}_{12}$ is even larger than that of $\mathrm{LaFe}_{4} \mathrm{P}_{12}$. (4) In contrast with the cases of pure La and Y metal in which the positive $d T_{c} / d P$ has been ascribed to the increased DOS of $4 \mathrm{f}(\mathrm{La})$ or $4 \mathrm{~d}(\mathrm{Y})$ bands near the Fermi level, ${ }^{29,30}$ the electronicstructure calculations ${ }^{13}$ for $\mathrm{LaFe}_{4} \mathrm{P}_{12}$ and other rare-earth filled skutterudites $^{31}$ have shown that the contribution from the $R$ to the DOS near the Fermi level is negligible. This is further confirmed by our band-structure calculations shown below. Taking these factors into account, the atomic properties of filling atoms should not play a major role for the positive $d T_{c} / d P$ observed in $R \mathrm{Fe}_{4} \mathrm{P}_{12}(R=\mathrm{La}, \mathrm{Y})$. However, it is obvious that the nonmagnetic character of the rare earth of $\mathrm{La}$ and $\mathrm{Y}$ is essential to make $R \mathrm{Fe}_{4} \mathrm{P}_{12}$ superconductive. The fact that both $\mathrm{LaFe}_{4} \mathrm{P}_{12}$ and $\mathrm{YFe}_{4} \mathrm{P}_{12}$ exhibit a positive $d T_{c} / d P$ raises another question: Are the Fe-based filled skutterudite superconductors unique with $d T_{c} / d P>0$ ? If so, why? In order to answer these questions satisfactorily, a comprehensive high-pressure study on filled skutterudite superconductors shown in Table I is required and is beyond the scope of the present study.

A positive $d T_{c} / d P$ of $\mathrm{YFe}_{4} \mathrm{P}_{12}$ is clearly correlated to the pressure-induced change of physical properties in the normal state. Unlike the measurements made with a self-clamp device, the pressure remains constant during the measurement of $\rho(T)$ on cooling down and warming up with the cubic anvil apparatus. Therefore, the $\rho(T)$ data in Fig. 5 contain more useful information for us to extract. The saturation of $\rho(T)$ at high temperatures reflects a relatively strong electron-phonon interaction. As shown in Fig. 5, pressure makes the feature of the resistivity saturation more pronounced, especially in the $\rho(T)$ under $8 \mathrm{GPa}$. Following the lead that pressure increases the electron-phonon coupling $\lambda$, we can interpret the enhancement of $T_{c}$ under pressure by the Allen-Dynes equation $T_{c} \sim \lambda^{1 / 2}$ (see Ref. 32). More interestingly, we have found the parameters in the power-law fitting to the $\rho(T)$ at low temperatures evolves obviously under pressure. As shown in Fig. 7, the residual resistivity $\rho_{0}$ changes very little over the pressure range to $8 \mathrm{GPa}$, which indicates that the grain boundary scattering remains quite small in this highly consolidated high-pressure product. A dramatic increase of $A$ and a reduction of $n$ from two under pressure in $\rho=\rho_{0}+A T^{n}$ are opposite to what we have normally seen in systems at the 

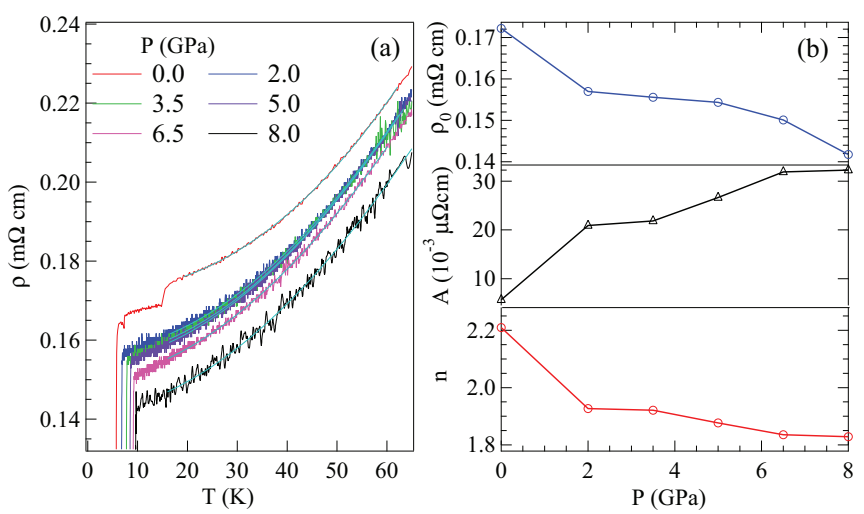

FIG. 7. (Color online) (a) A zoom-in plot of $\rho(T)$ at low temperatures and fitting to a power law $\rho=\rho_{0}+A T^{n}$ from $15-65 \mathrm{~K}$; (b) the pressure dependence of parameters in the fitting to the power law.

crossover from localized to itinerant electronic behavior, for example in $\mathrm{PrNiO}_{3}$ (see Ref. 33). These changes signal an increased mass enhancement under pressure.

In case the electron-phonon coupling $\lambda$ in $\mathrm{YFe}_{4} \mathrm{P}_{12}$ falls in a range of $0.45-0.50$ (see Refs. 25,34, and 35), $T_{c}$ can be described quantitatively by the McMillan equation:8,36

$$
T_{c} \approx \frac{\langle\omega\rangle}{1.20} \exp \left[-\frac{1.04(1+\lambda)}{\lambda-\mu^{*}(1+0.62 \lambda)}\right],
$$

where $\langle\omega\rangle$ is an average phonon frequency, and $\mu^{*}$ is the Coulomb repulsion that is usually set to 0.1 . The $e$ - $p$ coupling parameter is further defined as $\lambda \equiv N\left(E_{f}\right)\left\langle I^{2}\right\rangle / M\left\langle\omega^{2}\right\rangle$, where $N\left(E_{f}\right)$ is the DOS at Fermi level, $\left\langle I^{2}\right\rangle$ is the average squared electronic matrix element, $M$ is the molecular mass, and $\left\langle\omega^{2}\right\rangle$ is the average squared phonon frequency. By taking the logarithmic volume derivative of $T_{c}$ in Eq. (1), we can obtain the simple relation:

$$
-B \frac{d \ln T_{c}}{d P}=-\gamma+\Delta\left(\frac{d \ln \eta}{d \ln V}+2 \gamma\right),
$$

where $B$ is the bulk modulus, $\gamma \equiv-d \ln \langle\omega\rangle / d \ln V$ is the Grüneisen parameter, $\eta \equiv N\left(E_{f}\right)\left\langle I^{2}\right\rangle$ is the $H$ - $p$ that can be calculated directly by band-structure theory, and $\Delta \equiv 1.04 \lambda\left(1+0.38 \mu^{*}\right)\left[\lambda-\mu^{*}(1+0.62 \lambda)\right]^{-2}$. Since $\gamma(>0)$ is usually small relative to the second term on the right side of Eq. (2), the sign of the pressure derivative $d T_{c} / d P$ is determined by the relative magnitude of the two terms inside the bracket. As a well-behaved parameter under pressure, the $H-p \eta$ can be calculated theoretically. ${ }^{36,37}$ For simple $s, p$-metal superconductors, $d \ln \eta / d \ln V \approx-1$. Since $\Delta$ is always positive and $2 \gamma \approx+3$ to +5 , Eq. (2) can explain why most simple $s, p$-metal superconductors, e.g., $\mathrm{Sn}$ and $\mathrm{Pb}$, exhibit a negative $d T_{c} / d P$. On the other hand, for transition-metal superconductors, the electrons taking part in the superconductivity have a predominantly $d$ character, which often leads to a higher value of $N\left(E_{f}\right)$. In this case, theoretical calculations have pointed out that a larger $d \ln \eta / d \ln V \approx$ $-3 \sim-4$ is more appropriate. ${ }^{37}$ When the $|d \ln \eta / d \ln V|$ becomes larger than $2 \gamma, T_{c}$ is expected to increase with pressure, e.g., vanadium. ${ }^{38}$ Therefore, a large enhancement of $T_{c}$ with pressure for $R \mathrm{Fe}_{4} \mathrm{P}_{12}(R=\mathrm{La}$ and $\mathrm{Y})$ signals a $|d \ln \eta / d \ln V|>2 \gamma$, and a relatively large $|d \ln \eta / d \ln V|$ indicated that the $N\left(E_{f}\right)$ may undergo a dramatic increase under pressure. As shown below, this scenario is indeed confirmed by our band-structure calculations and the subsequent evaluation of $H$ - $p$ under 0 and $8 \mathrm{GPa}$ for $\mathrm{YFe}_{4} \mathrm{P}_{12}$.

We performed a full-potential linearized augmented-planewave (FLAPW) calculation on $\mathrm{YFe}_{4} \mathrm{P}_{12}$ and applied the rigid-muffin-tin (RMT) theory of Gaspari and Gyorffy ${ }^{39}$ to determine the value of $(H-p) \eta$ given by the expression for atom $A$ :

$$
\begin{aligned}
\eta & =\sum_{A} \eta_{A}=N\left(E_{f}\right) \sum_{A} n_{A}\left\langle I_{A}^{2}\right\rangle \\
& =\sum_{A} \sum_{l} 2(l+1) M_{(A,(l, l+1))}^{2} \frac{f_{l}^{A}}{2 l+1} \frac{f_{l+1}^{A}}{2 l+3},
\end{aligned}
$$

where $n_{A}$ is the number of type $A$ atom in the unit cell, $f_{l}^{A}=N_{l}^{A}\left(E_{f}\right) / N\left(E_{f}\right)$ is a relative partial state density for angular momentum $l$ and type A atom, and $N\left(E_{f}\right)$ is the total DOS at the $E_{f}, N_{l}^{A}\left(E_{f}\right)$ are the $l$ components of the DOS inside the muffin-tin (MT) spheres for type $A$ atom, and $N\left(E_{f}\right)=\sum_{A, l} n_{A} N_{l}^{A}\left(E_{f}\right) . M_{(A,(l, l+1))}$ is the electron-phonon matrix element, which is given in RMT by the expression ${ }^{40}$ in terms of the logarithmic derivatives $D_{l}\left(E_{f}\right)$ evaluated at $E_{f}$ and at the MT radius $(S)$ for type $A$ atom:

$$
\begin{aligned}
M_{(A,(l, l+1))}= & -\phi_{l}\left(E_{f}\right) \phi_{l+1}\left(E_{f}\right)\left[\left\{D_{l}\left(E_{f}\right)-l\right\}\right. \\
& \left.\times\left\{D_{l+1}\left(E_{f}\right)+l+2\right\}+\left\{E_{f}-V(S)\right\} S^{2}\right],
\end{aligned}
$$

where $\phi_{l}\left(E_{f}\right)$ is the partial wave amplitude at $E_{f}$, and $V(S)$ is the one-electron potential at $S$.

The necessary input to Eqs. (3) and (4) was generated from FLAPW calculations. In the calculations, 35 sampling k-points in the irreducible Brillouin zone (IBZ) are used for potential convergence, and 195 sampling k-points in IBZ are used for final band structures. About 5400 LAPW basis functions are used to obtain eigenvalues for each $k$-point. These were performed at the experimental crystal structures fixing the position of the pnictogen group, with respect to the transition metal, to $u=0.1472 a$ and $v=0.3519 a$. The MT sphere radii were set as $0.1907 a$ for Y, $0.1444 a$ for both Fe and P. The lattice parameter is $a=7.7913 \AA$ for ambient pressure and $a=7.66995 \AA$ for $8 \mathrm{GPa}^{41}$ For comparison, the FLAPW calculations were also performed for $\mathrm{YRu}_{4} \mathrm{P}_{12}$ in which the lattice parameter is $a=8.0298 \AA$ at ambient pressure and $a=7.90474 \AA$ at $8 \mathrm{GPa}^{41}$ The present calculations of the band structure and the Fermi surface at ambient pressure are in good agreement with previous literature. ${ }^{42,43}$

In the case of $\mathrm{YFe}_{4} \mathrm{P}_{12}$, two conduction bands (the 47th and 48th) cross the Fermi level, and the 48th band only crosses the Fermi level for $\mathrm{YRu}_{4} \mathrm{P}_{12}$. For $\mathrm{YFe}_{4} \mathrm{P}_{12}$, the 47th Fermi surface is sufficiently small compared to the 48th one. The $N\left(E_{f}\right) \mathrm{s}$ of both the 47th and 48th bands are 10.57 (8.13) states/Ry and 253.33 (287.47) states/Ry for ambient pressure ( $8 \mathrm{GPa}$ ), respectively. Therefore, only the 48 th band is presented in the evaluation of $H-p$. The angular momentum components $N_{l}\left(E_{f}\right)=\sum_{A} n_{A} N_{l}^{A}\left(E_{f}\right)$ of the DOS in the 48th band are shown in Figs. 8(a) and 8(b) for $\mathrm{YFe}_{4} \mathrm{P}_{12}$ and $\mathrm{YRu}_{4} \mathrm{P}_{12}$, respectively. The dominant components of $N_{l}\left(E_{f}\right)$ are those from both $p$ states $N_{p}\left(E_{f}\right)$ and $d$ states $N_{d}\left(E_{f}\right)$ for both 

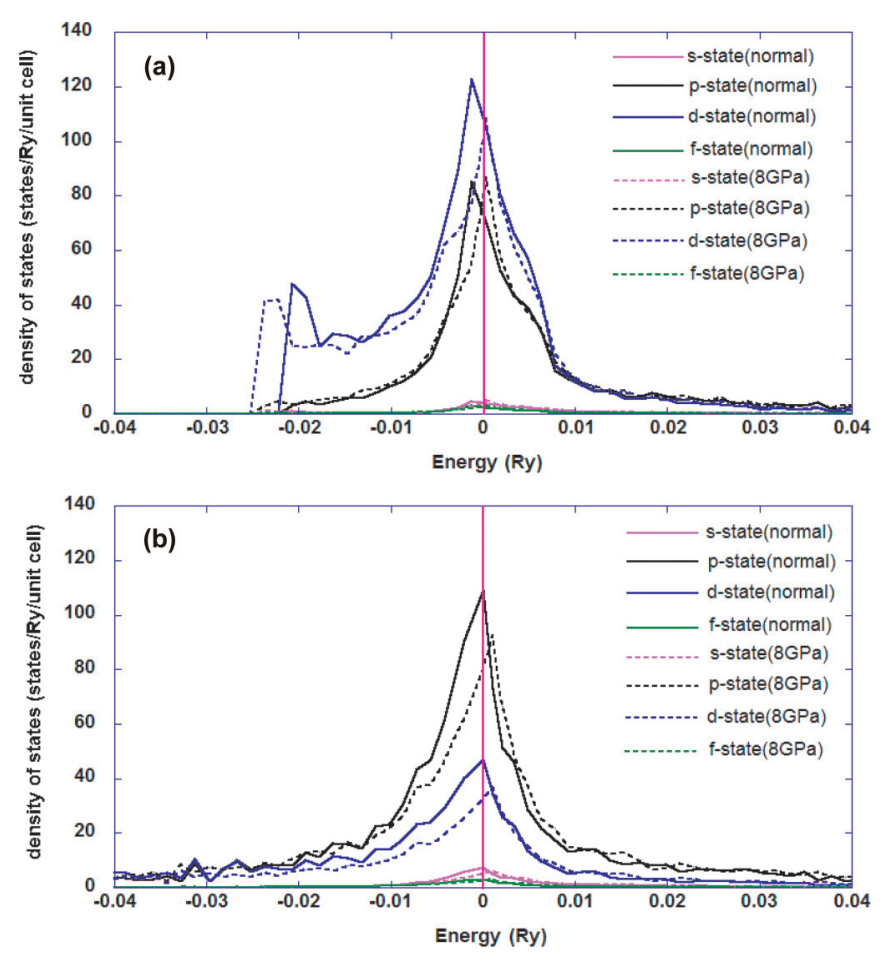

FIG. 8. (Color online) The angular momentum components of the density of states in the 48th band for normal pressure (solid line) and $8 \mathrm{GPa}$ (broken line) in the vicinity of the Fermi energy $E_{f}=0.0 \mathrm{Ry}$ : (a) $\mathrm{YFe}_{4} \mathrm{P}_{12}$, (b) $\mathrm{YRu}_{4} \mathrm{P}_{12}$.

$\mathrm{YFe}_{4} \mathrm{P}_{12}$ and $\mathrm{YRu}_{4} \mathrm{P}_{12}$. As shown in Table IV for $\mathrm{YFe}_{4} \mathrm{P}_{12}$, the $N_{p}\left(E_{f}\right)$ (mainly due to $\mathrm{P} 3 p$ electrons) and the $N_{d}\left(E_{f}\right)$ (mainly due to $\mathrm{Fe} 3 d$ electrons) increase under pressure, respectively. In contrast, both the $N_{p}\left(E_{f}\right)$ (mainly due to $\mathrm{P}$ $3 p$ electrons) and the $N_{d}\left(E_{f}\right)$ (mainly due to $\mathrm{Ru} 4 d$ electrons) decrease under pressure for $\mathrm{YRu}_{4} \mathrm{P}_{12}$. The calculated values of $\eta$ for $\mathrm{YFe}_{4} \mathrm{P}_{12}$ are $3.68 \mathrm{eV} / \AA^{2}$ and $5.16 \mathrm{eV} / \AA^{2}$ at ambient pressure and $8 \mathrm{GPa}$, respectively. Note that the value of the $\eta$ increases by about $40 \%$ under $8 \mathrm{GPa}$. In addition, the $\mathrm{Fe}$ contribution to $\eta$ is more than $70 \%$ for both ambient pressure and $8 \mathrm{GPa}$, and the dominant contributions come from $p-d$ and $d-f$ scattering. On the other hand, the $\eta$ of $\mathrm{YRu}_{4} \mathrm{P}_{12}$ decreases from the $4.88 \mathrm{eV} / \AA^{2}$ at ambient pressure to the $4.74 \mathrm{eV} / \AA^{2}$ at $8 \mathrm{GPa}$. In this case, the p contribution to $\eta$ is about $40 \%$, and $p-d$ and $d-f$ scattering are dominant. It is noted that the value of $\eta$ for niobium, which is a typical transitionmetal superconductor, is in the range $5.4 \sim 7.6 \mathrm{eV} / \AA^{2}$ (see Ref. 44) and is comparable to the value $\eta$ obtained here. We can thus conclude that the large variation of the $\eta$ under pressure for $\mathrm{YFe}_{4} \mathrm{P}_{12}$ is responsible for the observed increase of $T_{c}$ with pressure. The main contributions to the enhancement of $\eta$ are due to the increase of both $\mathrm{N}_{p}\left(E_{f}\right)$ and
TABLE IV. The atom-resolved and the total $H-p$ in $\mathrm{eV} / \AA^{2}$ for $\mathrm{YFe}_{4} \mathrm{P}_{12}$ and $\mathrm{YRu}_{4} \mathrm{P}_{12}$ at ambient pressure and $8 \mathrm{GPa}$. Angular momentum components of the density of states at $E_{f}$ in units of states/(Ry unit cell).

\begin{tabular}{lccccccc}
\hline \hline Sample & $\mathrm{P}(\mathrm{GPa})$ & $\mathrm{N}\left(E_{f}\right)_{p}$ & $\mathrm{~N}\left(E_{f}\right)_{d}$ & $\eta_{\mathrm{Y}}$ & $\eta_{\mathrm{Fe} / \mathrm{Ru}}$ & $\eta_{\mathrm{P}}$ & $\eta$ \\
\hline $\mathrm{YFe}_{4} \mathrm{P}_{12}$ & 0 & 70.16 & 104.36 & 0.06 & 2.80 & 0.82 & 3.68 \\
& 8 & 86.57 & 108.51 & 0.08 & 4.02 & 1.06 & 5.16 \\
$\mathrm{YRu}_{4} \mathrm{P}_{12}$ & 0 & 109.17 & 46.86 & 0.07 & 3.35 & 1.46 & 4.88 \\
& 8 & 90.33 & 38.27 & 0.08 & 3.34 & 1.32 & 4.74 \\
\hline \hline
\end{tabular}

$N_{d}\left(E_{f}\right)$ as shown in Table IV. Although there is no highpressure study on the variation of $T_{c}$ at present for $\mathrm{YRu}_{4} \mathrm{P}_{12}$, a small negative slope $d T_{c} / d P$ expected from the above analysis is consistent with the result of $\mathrm{LaRu}_{4} \mathrm{P}_{12}$.

In summary, we report comprehensive characterizations of filled skutterudite $\mathrm{YFe}_{4} \mathrm{P}_{12}$ synthesized under high pressure. As found in $\mathrm{LaFe}_{4} \mathrm{P}_{12}$, a $d T_{c} / d P=+1.0 \mathrm{~K} / \mathrm{GPa}$ at lower pressures and a $d T_{c} / d P=+0.53 \mathrm{~K} / \mathrm{GPa}$ to $5 \mathrm{GPa}$ have been obtained from the measurements of magnetization and resistivity under quasihydrostatic pressures up to $8 \mathrm{GPa}$. The detailed structural refinement on $\mathrm{YFe}_{4} \mathrm{P}_{12}$ revealed that the pressure effect on $T_{c}$ of the filled skutterudite should have little to do with that of the corresponding $R$ metals. From the analysis of transport property in the normal state of $\mathrm{YFe}_{4} \mathrm{P}_{12}$, pressure appears to increase the mass enhancement and to strengthen the electron-phonon interaction. The observed large $d T_{c} / d P>0$ of $\mathrm{YFe}_{4} \mathrm{P}_{12}$ was further explained by our band-structure calculations that show an enhancement of both $N\left(E_{f}\right)$ and the $H-p$ under pressure at least up to $8 \mathrm{GPa}$. On the other hand, similar calculations predict a $d T_{c} / d P<0$ for $\mathrm{YRu}_{4} \mathrm{P}_{12}$.

\section{ACKNOWLEDGMENTS}

We thank Ms. Shoko Nagasaki for her technical support in ISSP, University of Tokyo. J.G.C. greatly acknowledges the financial support of the JSPS fellowship for foreign researchers (Grant No. 12F02023) and the Chinese Academy of Sciences (Grant No. Y2K5016X51). K.M. is supported by Grant-in-Aid for Young Scientists B (No. 24740220) from the Ministry of Education, Culture, Sports, Science and Technology, Japan. J.S.Z. and J.B.G. are supported by NSF MIRT (DMR 1122603) and the Robert A Welch foundation (Grant F-1066). C.Q.J. was supported by NSF \& MOST of China through the research projects. Y.K. and C.S. were supported by a Grant-in-Aid for Scientific Research on Innovative Areas "Heavy Electrons" (No. 20102004) from the Ministry of Education, Culture, Sports, Science, and Technology, Japan, and a Grant-in-Aid for Scientific Research B (No. 23340092) from the Japan Society for the Promotion of Science.
*Corresponding author: jgcheng@iphy.ac.cn

${ }^{1}$ G. P. Meisner, Physica B \& C 108, 763 (1981).

${ }^{2}$ E. D. Bauer, N. A. Frederick, P.-C. Ho, V. S. Zapf, and M. B. Maple, Phys. Rev. B 65, 100506(R) (2002).
${ }^{3}$ E. D. Bauer, A. Slebarski, E. J. Freeman, C. Sirvent, and M. B. Maple, J. Phys.: Condens. Matter 13, 4495 (2001).

${ }^{4}$ C. Sekine, T. Uchiumi, I. Shirotani, and T. Yagi, Phys. Rev. Lett. 79, 3218 (1997). 
${ }^{5}$ H. Hidaka, I. Ando, H. Kotegawa, T. C. Kobayashi, H. Harima, M. Kobayashi, H. Sugawara, and H. Sato, Phys. Rev. B 71, 073102 (2005).

${ }^{6}$ C. Sekine, T. Uchiumi, I. Shirotani, K. Matsuhira, T. Sakakibara, T. Goto, and T. Yagi, Phys. Rev. B 62, 11581 (2000).

${ }^{7}$ B. C. Sales, D. Mandrus, and R. K. Williams, Science 272, 1325 (1996).

${ }^{8}$ J. S. Schilling, NATO Science Series 48, 345 (2001).

${ }^{9}$ L. E. DeLong and G. P. Meisner, Solid State Commun. 53, 119 (1985).

${ }^{10}$ W. E. Gardner and T. F. Smith, Phys. Rev. 138, A484 (1965).

${ }^{11}$ T. F. Smith and H. L. Luo, J. Phys. Chem. Solid. 28, 569 (1967).

${ }^{12}$ W. Jeitschko and D. Braun, Acta Cryst. B 33, 3401 (1977).

${ }^{13}$ D. Jung, M.-H. Whangbo, and S. Alvarez, Inorg. Chem. 29, 2252 (1990).

${ }^{14}$ I. Shirotani, Y. Shimaya, K. Kihou, C. Sekine, N. Takeda, M. Ishikawa, and T. Yagi, J. Phys.: Condens. Matter 15, S2201 (2003).

${ }^{15}$ J. J. Hamlin, V. G. Tissen, and J. S. Schilling, Phys. Rev. B 73, 094522 (2006).

${ }^{16}$ J.-G. Cheng, J.-S. Zhou, and J. B. Goodenough, Phys. Rev. B 81, 134412 (2010).

${ }^{17}$ J. Rodriguez-Carvajal, Physica B 192, 55 (1993).

${ }^{18}$ N. Mori, H. Takahashi, and N. Takeshita, High Press. Res. 24, 225 (2004).

${ }^{19}$ I. Shirotani, J. Hayashi, K. Takeda, R. Nakada, and Y. Ohishi, Physica B 382, 8 (2006).

${ }^{20}$ J. W. Kaiser and W. Jeitschko, J. Alloy. Comp. 291, 66 (1999).

${ }^{21}$ K. Takeda, S. Sato, J. Hayashi, C. Sekine, and I. Shirotani, J. Mag. Mag. Mater. 310, e1 (2007).

${ }^{22}$ H. Fukuoka and S. Yamanaka, Chem. Mater. 22, 47 (2010).

${ }^{23}$ R. O. Demchyna, S. I. Chykhriji, and Y. B. Kuzma, J. Alloy. Comp. 345, 170 (2002)

${ }^{24}$ H. G. von Schnering, D. Vu, and K. Peters, Z. Kristallogr.-New Cryst. Stru. 213, 459 (1998).

${ }^{25}$ G. K. Shenoy, D. R. Noakes, and G. P. Meisner, J. Appl. Phys. 53, 2628 (1982).

${ }^{26}$ Z. Fish and G. W. Webb, Phys. Rev. Lett. 36, 1084 (1976).

${ }^{27}$ K. Kadowaki and S. B. Woods, Solid State Commun. 58, 507 (1986).

${ }^{28}$ K. Kawamura and C. Sekine (private communication).

${ }^{29}$ W. E. Pickett, A. J. Freeman, and D. D. Koelling, Phys. Rev. B 22, 2695 (1980).

${ }^{30}$ Z. P. Yin, S. Y. Savrasov, and W. E. Pickett, Phys. Rev. B 74, 094519 (2006).
${ }^{31}$ R. Gumeniuk, W. Schnelle, H. Rosner, M. Nicklas, A. Leithe-Jasper, and Y. Grin, Phys. Rev. Lett. 100, 017002 (2008).

${ }^{32}$ P. B. Allen and B. Mitrovic, Solid State Phys. 37, 1 (1982).

${ }^{33}$ J.-S. Zhou, J. B. Goodenough, and B. Dabrowski, Phys. Rev. Lett. 94, 226602 (2005).

${ }^{34}$ Y. Nakai, K. Ishida, D. Kikuchi, H. Sugawara, and H. Sato, J. Phys. Soc. Jpn. 74, 3370 (2005).

${ }^{35}$ K. Magishi, T. Saito, K. Koyama, I. Shirotani, Y. Shimaya, K. Kihou, C. Sekine, N. Takeda, M. Ishikawa, and T. Yagi, Physica B 359-361, 883 (2005).

${ }^{36}$ W. L. McMillan, Phys. Rev. 167, 331 (1968).

${ }^{37}$ Hopfield, Physica 55, 41 (1971).

${ }^{38}$ M. Ishizuka, M. Iketani, and S. Endo, Phys. Rev. B 61, R3823 (2000).

${ }^{39}$ G. D. Gaspari and B. L. Gyorffy, Phys. Rev. Lett. 28, 801 (1972).

${ }^{40}$ H. L. Skriver and I. Mertig, Phys. Rev. B 32, 4431 (1985).

${ }^{41}$ J. Hayashi, K. Akahira, K. Matsui, H. Ando, Y. Sugiuchi, K. Takeda, C. Sekine, I. Shirotani, and T. Yagi, J. Phys.: Conf. Ser. 215, 012142 (2010).

${ }^{42}$ H. Sugawara, Y. Abe, Y. Aoki, H. Sato, M. Hedo, R. Settai, Y. Onuki, and H. Harima, J. Phys. Soc. Jpn. 69, 2938 (2000).

${ }^{43}$ S. R. Saha, H. Sugawara, Y. Aoki, H. Sato, Y. Inada, H. Shishido, R. Settai, Y. Onuki, and H. Harima, Phys. Rev. B 71, 132502 (2005).

${ }^{44}$ D. A. Papaconstantopoulos, L. L. Boyer, B. M. Klein, A. R. Williams, V. L. Morruzzi, and J. F. Janak, Phys. Rev. B 15, 4221 (1977).

${ }^{45}$ I. Shirotani, K. Ohno, C. Sekine, T. Yagi, T. Kawakami, T. Nakanishi, H. Takahashi, J. Tang, A. Matsushita, and T. Matsumoto, Physica B 281-282, 1021 (2000).

${ }^{46}$ N. Takeda and M. Ishikawa, J. Phys. Soc. Jpn. 69, 868 (2000).

${ }^{47}$ Y. Aoki, W. Higemoto, S. Sanada, K. Ohishi, S. R. Saha, A. Koda, K. Nishiyama, R. Kadono, H. Sugawara, and H. Sato, Physica B 359-361, 895 (2005).

${ }^{48}$ K. Arii, K. Igawa, H. Takahashi, M. Imai, M. Akaishi, and I. Shirotani, J. Phys.: Conf. Ser. 121, 052014 (2008).

${ }^{49}$ I. Shirotani, N. Araseki, Y. Shimaya, R. Nakata, K. Kihou, C. Sekine, and T. Yagi, J. Phys.: Condens. Matter 17, 4383 (2005).

${ }^{50}$ K. Kihou, I. Shirotani, Y. Shimaya, C. Sekine, and T. Yagi, Mater. Res. Bull. 39, 317 (2004).

${ }^{51}$ A. Miyake, K. Shimizu, C. Sekine, K. Kihou, and I. Shirotani, J. Phys. Soc. Jpn. 73, 2370 (2004).

${ }^{52}$ I. Shirotani, T. Uchiumi, K. Ohno, C. Sekine, Y. Nakazawa, K. Kanoda, S. Todo, and T. Yagi, Phys. Rev. B 56, 7866 (1997). 